\title{
Laser speckle contrast imaging of the skin: interest in processing the perfusion data
}

\author{
Anne Humeau-Heurtier • Benjamin Buard • \\ Guillaume Mahe $\cdot$ Pierre Abraham
}

Received: 30 November 2011/Accepted: 13 December 2011/Published online: 29 December 2011

(C) International Federation for Medical and Biological Engineering 2011

\begin{abstract}
Laser speckle contrast imaging (LSCI) is a recent clinical powerful tool to obtain full-field images of microvascular blood perfusion. The technique relies on laser speckle obtained by the interactions between coherent monochromatic radiations and the tissues under study. From these speckle images, contrast values are determined and instantaneous map of the perfusion are computed. LSCI has gained increased attention in the last years and is now additional to laser Doppler flowmetry (LDF). In spite of the growing interest for LSCI in skin clinical research, very few LSCI perfusion data processing have been published from now to extract physiologically-linked indices. By opposition, numerous signal processing works have been dedicated to the processing of LDF signals. The latter works proposed methodological processing procedures to extract information reflecting underlying microvascular mechanisms such as myogenic, neurogenic and endothelial activities. Our goal herein is to report on the potentialities of studies dedicated to the processing of LSCI perfusion data. Linear and nonlinear analyses could be of interest to improve the understanding of LSCI images.
\end{abstract}

\footnotetext{
A. Humeau-Heurtier ( $\square)$

Laboratoire d'Ingénierie des Systèmes Automatisés (LISA), Département GEII, Université d'Angers, Institut Universitaire de Technologie, 4 boulevard Lavoisier, BP 42018 49016, Angers cedex, France

e-mail: anne.humeau@univ-angers.fr

B. Buard

Angers, France

G. Mahe · P. Abraham

Laboratoire de Physiologie et d'Explorations Vasculaires, UMR CNRS 6214-INSERM 1083, Centre Hospitalier Universitaire d'Angers, 49933 Angers cedex 9, France
}

Keywords Laser speckle contrast imaging . Microcirculation - Signal processing - Image processing . Laser Doppler flowmetry

In clinical research, the real-time monitoring of skin microvascular blood perfusion can be performed, among others, with laser Doppler flowmetry (LDF) and laser speckle contrast imaging (LSCI) (see, e.g., [7, 13, 18, 26, 43, 46]). LDF has been proposed in the 1970's [45] to monitor the microvascular blood perfusion in a small volume of tissue (approximately $1 \mathrm{~mm}^{3}$ in skin when a $780 \mathrm{~nm}$ laser wavelength is used). Since that time, many works have led to the improvements of the technique (see, e.g., $[1-6,10,29,38,39,47])$. LSCI is a more recent technique developed in the mid 1990s. It relies on the speckle phenomenon generated by the interactions between coherent monochromatic radiations and a scattering medium [7]. The first speckle imagers were commercialized very recently and from this time LSCI has been the subject of an increasing number of papers (see, e.g., [7, 30, 31, 40]). LSCI and LDF have found widespread skin vascular application among which we can cite the reperfusion monitoring of skin flaps, the quantification of peripheral vascular diseases, the perfusion monitoring of burns, wounds and foot ulcers. LSCI has the advantage, over LDF, of being a noncontact method and giving a twodimensional image of the perfusion, thus reducing the spatial variability of the measure [42].

In the last years, several LDF models and simulations $[9,16,22-24,27,35-37]$ and many LDF signal processing studies have been published. A number of these signal processing works use wavelets to extract data from the heart rate, respiration, myogenic, neurogenic and endothelial activities (see, e.g., [12, 17, 44]). Other works 
proposed fractal or multifractal analyses to better understand LDF signals (see, e.g., [15, 21, 28]). Moreover, as the LDF technique is very sensitive to movements, signal processing to reduce the movement artifacts have also been published [19, 20, 25]. Furthermore, some authors analyzed the sample entropy of LDF signals from healthy subjects and from patients with systemic sclerosis [8]. This list of signal processing works performed on LDF data is not exhaustive but shows that a high number of studies took advantage of the signal processing capacities to go forward in the understanding of LDF signals. From all these works, diagnosis approaches have also become easier.

For LSCI data, images can be processed into two ways: either the images are processed, one by one. In that case, image processing tools are used and spatial informations are processed and then studied with time evolution (comparing the results from one image to the others); either pixels values are averaged over an area, called region of interest (ROI) [41], and then this perfusion value is analyzed with time. In the latter case, signal processing tools are used to analyze evolution of blood perfusion with time. Signal processing studies performed on LDF signals may be of interest for signals obtained with LSCI ROI. A recent study proposed a method aiming at "denoising" perfusion signals computed from a ROI of LSCI images [32]. This processing work shows that the blood flow monitoring over moving skin surfaces can be possible with LSCI. However, except this study, to the best of our knowledge most of the LSCI processing works have been dedicated to raw speckle images or to cerebral applications, not to LSCI images for skin applications. Analyzing cerebral blood flow, some authors proposed a registered laser speckle contrast analysis method to remove the noise induced by respiration and/or heart beating [34]. They registered raw speckle images with a convolution kernel, normalized correlation metric and cubic B-spline interpolator and then constructed the contrast image [34]. A model based reconstruction for simultaneously image cerebral blood flow and de-oxygen hemoglobin distribution has also been proposed; for this purpose the authors used raw speckle images [33]. A processing scheme to extract temporal correlation parameters from the speckle contrast measured with a static or slow-evolving background has also been reported; the applications are performed on the cerebral hemodynamic response [48]. Some authors proposed a fractal characterization of LSCI images of the rat brain cortex [15]. Others used a boxcounting approach (fractal analysis) of self-mixing speckle signal in velocity sensing [14]. In a more general context, a fractal-theory-based stochastic approach on speckle images has been reported to approximate the diffusion of light [11]. The authors mention a possible application to study the diffusion of light in human skin.
All these LSCI processes can be interesting. However, they are difficult to use in clinical routines because the user does not always have access to these raw images (the manufacturers often give the perfusion images only, not the raw data). Moreover, these processes have not been proposed for skin study. Linear and nonlinear signal processing studies performed on LDF signals could be applied on signals extracted from LSCI data (ROI perfusion values). Therefore, indices computed from LSCI images and reflecting the microvascular underlying mechanisms could possibly be as instructive as the ones computed from LDF signals. Furthermore, some of the one-dimensional studies performed on LDF signals could be extended in a twodimensional plane to process LSCI perfusion images. As a result, potentially, much more processing capacities are available from LSCI perfusion images than from LDF signals. We, therefore, encourage the image and signal processing community to study LSCI perfusion images with the goal to extract skin physiological information needed by the clinicians.

\section{References}

1. Arildsson M, Nilsson GE, Strömberg T (2002) Spectral signature and heterodyne efficiency for different wavelengths in laser Doppler flowmetry. Med Biol Eng Comput 40(1):85-89

2. Binzoni T, Boggett D, VanDe Ville D (2011) Laser-Doppler flowmetry at large interoptode spacing in human tibia diaphysis: Monte Carlo simulations and preliminary experimental results. Physiol Meas 32(11):N33-N53

3. Cai H, Rohman H, Larsson SE, Oberg PA (1996) Laser Doppler flowmetry: characteristics of a modified single-fibre technique. Med Biol Eng Comput 34(1):2-8

4. Chen YY, Lin YH, Jan IC, Liu RS, Chou NK, Jan GJ (2004) Adaptive processing bandwidth adjustment for laser Doppler flowmetry. Med Biol Eng Comput 42(3):277-281

5. Clough G, Chipperfield A, Byrne C, de Mul F, Gush R (2009) Evaluation of a new high power, wide separation laser Doppler probe: potential measurement of deeper tissue blood flow. Microvasc Res 78(2):155-161

6. Deblen H, Oberg PA (1991) Frequency stabilisation of multimode helium-neon lasers in laser Doppler flowmetry. Med Biol Eng Comput 29(5):470-474

7. Draijer M, Hondebrink E, van Leeuwen T, Steenbergen W (2009) Review of laser speckle contrast techniques for visualizing tissue perfusion. Lasers Med Sci 24(4):639-651

8. Figueiras E, Roustit M, Semedo S, Ferreira LF, Crascowski JL, Humeau A (2011) Sample entropy of laser Doppler flowmetry signals increases in patients with systemic sclerosis. Microvasc Res 82(2):152-155

9. Fredriksson I, Larsson M, Stromberg T (2010) Model-based quantitative laser Doppler flowmetry in skin. J Biomed Opt 15(5):057002

10. Gush RJ, King TA (1991) Discrimination of capillary and arteriovenular blood flow in skin by laser Doppler flowmetry. Med Biol Eng Comput 29(4):387-392

11. Guyot S, Péron MC, Deléchelle E (2004) Spatial speckle characterization by Brownian motion analysis. Phys Rev E Stat Nonlin Soft Matter Phys 70(4 Pt 2):046618 
12. Hafner HM, Brauer K, Radke C, Eichner M, Strolin A (2009) Wavelet analysis of Laser Doppler Flux time series of tumor and inflammatory associated neoangiogenesis. Differences in rhythmical behavior. Clin Hemorheol Microcirc 43(3):191-201

13. Hagblad J, Lindberg LG, Kaisdotter Andersson A, Bergstrand S, Lindgren M, Ek AC, Folke M, Linden M (2010) A technique based on laser Doppler flowmetry and photoplethysmography for simultaneously monitoring blood flow at different tissue depths. Med Biol Eng Comput 48(5):415-422

14. Han D, Wang M, Zhou J (2008) Fractal analysis of self-mixing speckle signal in velocity sensing. Opt Express 16(5):3204-3211

15. Herman P, Kocsis L, Eke A (2009) Fractal characterization of complexity in dynamic signals: application to cerebral hemodynamics. Methods Mol Biol 489:23-40

16. Humeau A, Saumet JL, L'Huillier JP (2000) Simplified model of laser Doppler signals during reactive hyperaemia. Med Biol Eng Comput 38(1):80-87

17. Humeau A, Koïtka A, Abraham P, Saumet JL, L'Huillier JP (2004) Spectral components of laser Doppler flowmetry signals recorded in healthy and type 1 diabetic subjects at rest and during a local and progressive cutaneous pressure application: scalogram analyses. Phys Med Biol 49(17):3957-3970

18. Humeau A, Steenbergen W, Nilsson H, Strmberg T (2007) Laser Doppler perfusion monitoring and imaging: novel approaches. Med Biol Eng Comput 45(5):421-435

19. Humeau A, Trzepizur W, Rousseau D, Chapeau-Blondeau F, Abraham P (2008) Fisher information and Shannon entropy for on-line detection of transient signal high-values in laser Doppler flowmetry signals of healthy subjects. Phys Med Biol 53(18): 5061-5076

20. Humeau A, Trzepizur W, Rousseau D, Chapeau-Blondeau F, Abraham P (2009) Localization of transient signal high-values in laser Doppler flowmetry signals with an empirical mode decomposition. Med Phys 36(1):18-21

21. Humeau A, Buard B, Mahé G, Chapeau-Blondeau F, Rousseau D, Abraham P (2010) Multifractal analysis of heart rate variability and laser Doppler flowmetry fluctuations:comparison of results from different numerical methods. Phys Med Biol 55(20): 6279-6297

22. Jakobsson A, Nilsson GE (1993) Prediction of sampling depth and photon pathlength in laser Doppler flowmetry. Med Biol Eng Comput 31(3):301-307

23. Jentink HW, de Mul FF, Hermsen RG, Graaff R, Greve J (1990) Monte Carlo simulations of laser Doppler blood flow measurements in tissue. Appl Opt 29(16):2371-2381

24. Jentink HW, Mul FF, Graaff R, Suichies HE, Aarnoudse JG, Greve J (1991) Laser Doppler flowmetry: measurements in a layered perfusion model and Monte Carlo simulations of measurements. Appl Opt 30(18):2592-2597

25. Karlsson MG, Casimir-Ahn H, Lonn U, Wardell K (2003) Analysis and processing of laser Doppler perfusion monitoring signals recorded from the beating heart. Med Biol Eng Comput 41(3):255-262

26. Kim SW, Kim SC, Nam KC, Kang ES, Im JJ, Kim DW (2008) A new method of screening for diabetic neuropathy using laser Doppler and photoplethysmography. Med Biol Eng Comput 46(1):61-67

27. Koelink MH, de Mul FF, Greve J, Graaff R, Dassel AC, Aarnoudse JG (1994) Laser Doppler blood flowmetry using two wavelengths: Monte Carlo simulations and measurements. Appl Opt 33(16):3549-3558

28. Liao F, Struck BD, Macrobert M, Jan YK (2011) Multifractal analysis of nonlinear complexity of sacral skin blood flow oscillations in older adults. Med Biol Eng Comput 49(8):925-934

29. Liebert A, Leahy M, Maniewski R (1998) Multichannel laserDoppler probe for blood perfusion measurements with depth discrimination. Med Biol Eng Comput 36(6):740-747
30. Mahe G, Durand S, Humeau A, Leftheriotis G, Rousseau P, Abraham P (2011) Air movements interfere with laser speckle contrast imaging recordings. Lasers Med Sci

31. Mahe G, Haj-Yassin F, Rousseau P, Humeau A, Durand S, Leftheriotis G, Abraham P (2011) Distance between laser head and skin does not influence skin blood flow values recorded by laser speckle imaging. Microvasc Res 82(3):439-442

32. Mahé G, Rousseau P, Durand S, Bricq S, Leftheriotis G, Abraham P (2011) Laser speckle contrast imaging accurately measures blood flow over moving skin surfaces. Microvasc Res 81(2):183-188

33. Miao P, Li N, Rege A, Tong S, Thakor N (2009) Model based reconstruction for simultaneously imaging cerebral blood flow and De-oxygen hemoglobin distribution. Conf Proc IEEE Eng Med Biol Soc 2009:3236-3293

34. Miao P, Rege A, Li N, Thakor NV, Tong S (2010) High resolution cerebral blood flow imaging by registered laser speckle contrast analysis. IEEE Trans Biomed Eng 57(5):1152-1157

35. de Mul FF, Koelink MH, Kok ML, Harmsma PJ, Greve J, Graaff R, Aarnoudse J (1995) Laser Doppler velocimetry and Monte Carlo simulations on models for blood perfusion in tissue. Appl Opt 34(28):6595-6611

36. de Mul FF, Steenbergen W, Greve J (1999) Doppler Monte Carlo simulations of light scattering in tissue to support laser-Doppler perfusion measurements. Technol Health Care 7(2-3):171-183

37. de Mul FF, Blaauw J, Smit RJ, Rakhorst G, Aarnoudse JG (2009) Time development models for perfusion provocations studied with laser-Doppler flowmetry, applied to iontophoresis and PORH. Microcirculation 16(7):559-571

38. Obeid AN (1993) In vitro comparison of different signal processing algorithms used in laser Doppler flowmetry. Med Biol Eng Comput 31(1):43-52

39. Obeid AN, Boggett DM, Barnett NJ, Dougherty G, Rolfe P (1988) Depth discrimination in laser Doppler skin blood flow measurement using different lasers. Med Biol Eng Comput 26(4):415-419

40. O'Doherty J, McNamara P, Clancy NT, Enfield JG, Leahy MJ (2009) Comparison of instruments for investigation of microcirculatory blood flow and red blood cell concentration. J Biomed Opt 14(3):034025

41. Rousseau P, Mahé G, Haj-Yassin F, Durand S, Humeau A, Leftheriotis G, Abraham P (2011) Increasing the "region of interest" and "time of interest", both reduce the variability of blood flow measurements using laser speckle contrast imaging. Microvasc Res 82(1):88-91

42. Roustit M, Millet C, Blaise S, Dufournet B, Cracowski JL (2010) Excellent reproducibility of laser speckle contrast imaging to assess skin microvascular reactivity. Microvasc Res 80(3):505-511

43. Roustit M, Cracowski JL (2011) Non-invasive assessment of skin microvascular function in humans: an insight into method. Microcirculation. doi:10.1111/j.1549-8719.2011.00129.x

44. Stefanovska A, Bracic M, Kvernmo HD (1999) Wavelet analysis of oscillations in the peripheral blood circulation measured by laser Doppler technique. IEEE Trans Biomed Eng 46(10):1230-1239

45. Stern MD (1975) In vivo evaluation of microcirculation by coherent light scattering. Nature 254(5495):56-58

46. Tew GA, Klonizakis M, Crank H, Briers JD, Hodges GJ (2011) Comparison of laser speckle contrast imaging with laser Doppler for assessing microvascular function. Microvasc Res 82(3):326-332

47. Wojtkiewicz S, Liebert A, Rix H, Maniewski R (2011) Evaluation of algorithms for microperfusion assessment by fast simulations of laser Doppler power spectral density. Phys Med Biol 56(24):7709-7723

48. Zakharov P, Vlker AC, Wyss MT, Haiss F, Calcinaghi N, Zunzunegui C, Buck A, Scheffold F, Weber B (2009) Dynamic laser speckle imaging of cerebral blood flow. Opt Express 17(16):13904-13917 